Rapid Reviews COVID-19

\title{
Review 2: "Prisons and Pandemics"
}

\author{
Natalie Pifer ${ }^{1}$ \\ 1 University of Rhode Island, Criminology and Criminal Justice
}

Published on: Aug 20, 2020

DOI: $10.21428 / 2 \mathrm{e} 3983 f 5.8 \mathrm{a} 2 \mathrm{~cd} 283$

License: Creative Commons Attribution 4.0 International License (CC-BY 4.0). 


\section{$\underline{\text { RR:C19 Evidence Scale rating by reviewer: }}$}

- Potentially informative. The main claims made are not strongly justified by the methods and data, but may yield some insight. The results and conclusions of the study may resemble those from the hypothetical ideal study, but there is substantial room for doubt. Decision-makers should consider this evidence only with a thorough understanding of its weaknesses, alongside other evidence and theory. Decisionmakers should not consider this actionable, unless the weaknesses are clearly understood and there is other theory and evidence to further support it.

******************************************

\section{Review:}

As this piece is not an empirical one, several of the review criteria are not relevant. As a punishment scholar who is increasingly engaged with public health literature, I found the perspective of two experts in Bioethics on Prisons and Pandemics to be a worthwhile contribution.

Overall, they have done a nice job applying existing knowledge to the new context of the pandemic and the piece is well framed and well written. The citations to the very recent popular press and research center pieces are good ones, and the citations to public health literature seem to be well curated for the article (though I am not an expert in this literature).

I was surprised, however, to not see any integration of the work being done by the researchers at AMEND at the University of California, San Francisco. Dr. Williams and Cyrus Ahalt have made several important contributions already (Ahalt has a piece in the Appeal on the shared fate of the jailed and jailer, that would be very useful to extend the practical argument about the protection of staff and Williams, et al. wrote about the slippage between solitary confinement and medical isolation for the Health Affairs Blog that would do nicely in extending both legal and ethical arguments, for example).

Depending on the article's intended, primary audience, there are some additional perspectives from the punishment and society and socio-legal literatures that might be useful to integrate in order to strengthen the arguments. Jonathan Simon's work may be especially useful here. His book Mass Incarceration on Trial, and especially the chapter on Coleman v Wilson, would help bolster the impossibility of "doing" medical 
care in prisons, even without the pandemic, and would be relevant to all three arguments. He also engages with the concept of dignity in a thoughtful way.

In my opinion, the assumption made in footnote 127 deserves far more attention that one sentence. Criminal justice struggles mightily with the operationalization of "public safety" and deciding who threatens it. California's experiment in Realigning Corrections centered on the so-called "triple nons," or those who have been convicted of non-violent, non-sexual, non-serious crimes might offer some support for the author's focus (though Simon and others work would complicate it-who do we leave behind by focusing on just the nons in criminal justice reform efforts AND in pandemic response plans? And, is that ethical?).

Again, I think this centers on the intended audience because, in my field, concepts like threat and risk would get much more attention, and the authors may find the punishment and society literature useful here. 